\title{
Platelet to lymphocyte ratio predicting 6-month primary patency of drug-coated balloon for femoropopliteal disease
}

\author{
Yanhua Zhen, Zhihui Chang, Zhaoyu Liu and Jiahe Zheng ${ }^{*}$ (D)
}

\begin{abstract}
Background: Inflammatory reaction is an essential factor in the occurrence, development and prognosis of femoropopliteal disease (FPD). The ratio of platelets to lymphocytes (PLR) is a new indicator reflecting platelet aggregation and burden of systemic inflammation. Our study is to explore the association between preoperative platelet-to-lymphocyte ratio (pre-PLR) and 6-month primary patency (PP) after drug-coated balloon (DCB) in FPD.

Methods: There were 70 patients who underwent DCB for FPD contained in the study. According to 6-month PP, patients were divided into group A (PP $\geq 6$ months, $n=54$ ) and group $B$ (PP $<6$ months, $n=16$ ). Logistic regression analysis was used to identify potential predictors for 6-month PP after DCB in FPD. A receiver operating characteristic (ROC) curve analysis was used to identify the cut-off value of pre-PLR to predict 6-month PP.

Results: Logistic regression analysis showed that pre-PLR (OR: 1.008, 95\% Cl: 1.001-1.016, $P=0.031$ ) and lesion length $>10 \mathrm{~cm}$ (OR: $4.305,95 \% \mathrm{Cl}: 1.061-17.465, P=0.041)$ were independently predictive for 6 -month PP. The cutoff value of pre-PLR obtained from the ROC analysis was 127.35 to determine 6-month PP with the area of 0.839 . Subgroup analysis was conducted based on the cutoff value of pre-PLR. The 6-month PP in the group of pre-PLR $<$ 127.35 was higher than that of pre-PLR $\geq 127.35$ group $(p<0.001)$.
\end{abstract}

Conclusions: The present study indicated that an elevated pre-PLR was an effective additional indicator for predicting early PP in FPD after DCB.

Keywords: Platelet, Lymphocyte, Femoropopliteal disease, Drug-coated balloon, Primary patency

\section{Background}

A great deal of literature has shown that the inflammatory reaction is an essential factor in the occurrence, development and prognosis of femoropopliteal disease (FPD) [1-4]. Previous studies indicate that platelets are critical in the formation of atherosclerosis, not only as a mediator of thrombosis, but also as inflammatory cells, involved in immune-mediated plaque instability and the process of chronic atherosclerosis [5-7]. In addition, lymphocytes play a regulatory role in inflammatory response, and have a protective effect on atherosclerosis [8]. During the inflammatory response, the number of lymphocytes decrease due to accelerated apoptosis [9, 10].The ratio of platelets to lymphocytes (PLR) is a new

* Correspondence: zhengjh120624@126.com

Department of Radiology, Shengjing Hospital of China Medical University,

Shenyang 110004, 36, Sanhao Street, Heping District, Shenyang City, China indicator reflecting platelet aggregation and burden of systemic inflammation. It represents two opposite associations which are more stable relative to absolute platelet or lymphocyte counts [11]. Previous reports have shown that PLR is closely related to the severity of heart disease and the prognosis after interventional therapy $[12,13]$. And for patients suffering from carotid artery stenosis, PLR was observed to be an independent variable to predict stroke [14]. However, the relationship between preoperative platelet-to-lymphocyte ratio (prePLR) and prognosis of patients with FPD undergoing percutaneous transluminal angioplasty (PTA) with drugcoated balloon (DCB) is unknown, it is supposed that pre-PLR was predictive of 6-month PP rate after DCB for FPD.

(c) The Author(s). 2020 Open Access This article is distributed under the terms of the Creative Commons Attribution 4.0 International License (http://creativecommons.org/licenses/by/4.0/), which permits unrestricted use, distribution, and reproduction in any medium, provided you give appropriate credit to the original author(s) and the source, provide a link to the Creative Commons license, and indicate if changes were made. The Creative Commons Public Domain Dedication waiver (http://creativecommons.org/publicdomain/zero/1.0/) applies to the data made available in this article, unless otherwise stated. 


\section{Methods}

The Shengjing Hospital of China Medical University institutional review board approved this retrospective study with a waiver of informed consent. Seventy patients who underwent DCB for FPD in our institution were contained in our analysis. The main exclusion criteria included in-stent stenosis and any diseases that were referred to infectious diseases, malignant tumor and autoimmune diseases.

Baseline clinical characteristics (age, man, hypertension, smoke, diabetes, hyperlipemia, cardiovascular disease), lesion characteristics (severe calcium, critical limb ischemia (CLI), total occlusion, outflow, lesion length), bail-out stent, the counts of preoperative white blood cell (WBC), mean platelet volume (MPV), platelets, lymphocytes, and neutrophils were obtained from medical records. Severe calcium was defined as calcium lesion $\geq 180^{\circ}$ (or both sides of the vessel at the same location) and $\geq$ half total lesion length [15]. PLR was the ratio of absolute count of platelets to lymphocytes generated from the blood samples, and neutrophillymphocyte ratio (NLR) was the ratio of absolute count of neutrophils to lymphocytes.

All patients received dual antiplatelet therapy with acetylsalicylic acid (ASA) $(100 \mathrm{mg} / \mathrm{d})$ and clopidogrel $(75 \mathrm{mg} / \mathrm{d})$ for 5 days or a preload of $300 \mathrm{mg}$ of ASA and clopidogrel before DCB. Pre-dilatation with uncoated balloon was conducted conventionally before DCB. The DCB used in this study was coated with paclitaxel at $3 \mu \mathrm{g} / \mathrm{mm}^{2}$, and the method of use was as described previously [16].

Follow-up with a primary patency (PP) at 6 months was the primary outcome, which was considered as no clinically driven target lesion revascularization or restenosis. Stenosis more than $50 \%$ by duplex ultrasound with a peak systolic velocity ratio $>2.4$ was identified as restenosis.

\section{Statistical analysis}

Data were calculated by SPSS 25.0 (SPSS Inc., Chicago, Illinois). Quantitative data were expressed as mean with standard deviation or median with interquartile, and qualitative data were expressed with frequencies and percentages. For normally distributed data comparisons were tested by Chi - square test or the Student $t$ test. Analyses were performed using non-parametric statistical methods when variables showed markedly nonnormal distribution. Significant univariate factors with $p<0.1$ were further tested in the multivariable model. And odds ratio (OR) was used with $95 \%$ confidence interval $(\mathrm{CI})$ to present potential predictors for 6month PP. A receiver operating characteristic (ROC) curve analysis was constructed to judge the prediction ability of pre-PLR in 6-month PP. A two tailed $P<0.05$ indicated statistical significance.

\section{Results}

Patient characteristics were showed in Table 1. According to 6-month $\mathrm{PP}$, we divided the patients into group A (PP $\geq 6$ months, $n=54$ ) and group $\mathrm{B}$ (PP $<6$ months, $n=$ 16). Significant differences were observed between the two groups concerning lesion length $>10 \mathrm{~cm}$, preplatelets, pre-lymphocytes, MPV, pre-PLR $(p<0.05)$, no differences in other clinical and lesion characteristics were reported in the two groups $(p>0.05)$.

On univariate analysis, pre-PLR, lesion length $>10 \mathrm{~cm}$, CLI, MPV and outflow were significant prognostic factors, and multivariate logistic regression analysis showed that pre-PLR (OR: $1.008,95 \%$ CI: $1.001-1.016, P=$ $0.031)$ and lesion length $>10 \mathrm{~cm}$ (OR: 4.305, 95\% CI: $1.061-17.465, P=0.041)$ were independently predictive for 6-month PP (Table 2).

The cutoff value of pre-PLR calculated from the ROC curve analysis was 127.35 for determination of 6-month PP. The area under the ROC curve was 0.839 (95\% CI: $0.712-0.965, P<0.001)$ with the sensitivity of $81.3 \%$ and specificity of $79.6 \%$, respectively (Fig. 1 ).

Subgroup analysis was conducted based on the cutoff value of pre-PLR (127.35), the 6-month PP in the group of pre-PLR $<127.35$ was higher than that of pre-PLR $\geq$ 127.35 group $(p<0.001)$.

\section{Discussion}

In this study, we investigated the association between pre-PLR and the prognosis of FPD. The results indicated that pre-PLR and lesion length $>10 \mathrm{~cm}$ were independently predictive for 6-month PP after DCB for FPD. The cutoff value of pre-PLR was 127.35 with the sensitivity of $81.3 \%$ and specificity of $79.6 \%$, respectively. Subgroup analysis showed that the 6-month PP in the group of pre-PLR $<127.35$ was higher than that of pre-PLR $\geq$ 127.35 group.

Increased platelets and platelet activation are key factors in the development of thrombosis and atherosclerosis $[17,18]$. When atherosclerotic plaque ruptures or blood vessels are damaged after PTA, platelets in this area adhere and aggregate, which promote the development of mural thrombus or occlusive thrombus, thus leading to the restenosis of lower limb artery disease $[19,20]$. Closely related to these conclusions, in the current study, the count of platelets was higher in group B compared with group A. In addition, platelets can interact with other inflammatory cells, resulting in a cascade of inflammation and atherosclerosis at the vessel wall [6].

Low lymphocytes are common manifestations of acute inflammatory reaction [21]. It is known that lymphocytes participate in the whole process of the occurrence, development and prognosis of atherosclerosis [22]. The low lymphocyte count is related to reduced hemodynamics and aerobic capacity. Lymphocytes apoptosis was observed in atherosclerotic lesions including plaque growth, lipid core 
Table 1 Comparison of demographic and clinical characteristics of the 70 patients grouped by 6-month primary patency

\begin{tabular}{|c|c|c|c|}
\hline & Group $A^{a}(n=54)$ & Group $\mathrm{B}^{\mathrm{b}}(n=16)$ & $\mathrm{p}$ \\
\hline Man, n (\%) & $39(72.2)$ & 15(93.8) & 0.074 \\
\hline Age, mean (SD) & $65.52(10.55)$ & $68.38(8.46)$ & 0.325 \\
\hline Hypertension, n (\%) & $37(68.5)$ & $12(75.0)$ & 0.622 \\
\hline Smoke, n (\%) & 42(77.8) & $10(62.5)$ & 0.223 \\
\hline Diabetes, n (\%) & 29(53.7) & 12(75.0) & 0.132 \\
\hline Hyperlipemia, n (\%) & $13(24.1)$ & $5(31.3)$ & 0.567 \\
\hline Cardiovascular disease, n (\%) & 21(38.9) & $10(62.5)$ & 0.097 \\
\hline Severe calcium, n (\%) & $5(9.3)$ & $1(6.3)$ & 1.000 \\
\hline CLI, n (\%) & $20(37.0)$ & $10(62.5)$ & 0.073 \\
\hline Total occlusion, n (\%) & $38(70.4)$ & $11(68.8)$ & 0.902 \\
\hline \multicolumn{4}{|l|}{ Outflow, n (\%) } \\
\hline 1 & 10(18.5) & $7(43.8)$ & \\
\hline 2 & 14(25.9) & $3(18.8)$ & \multirow[t]{2}{*}{0.087} \\
\hline 3 & $30(55.6)$ & $6(37.5)$ & \\
\hline Bail-out stent, n (\%) & $6(11.1)$ & $2(12.5)$ & 0.879 \\
\hline Lesion length > 10 cm, n (\%) & $20(37.0)$ & $12(75.0)$ & 0.008 \\
\hline WBC, median (IQR) & $6.86(5.86-9.18)$ & $6.62(5.01-9.34)$ & 0.727 \\
\hline Platelets, mean (SD) & $203.39(65.56)$ & 249.13(75.45) & 0.021 \\
\hline MPV, median (IQR) & $9.00(8.37-9.80)$ & $8.45(8.00-8.90)$ & 0.070 \\
\hline Neutrophils, median (IQR) & $4.35(3.6-6.0)$ & $3.65(2.85-6.82)$ & 0.511 \\
\hline Lymphocytes, median (IQR) & $1.95(1.57-2.60)$ & $1.50(1.20-1.78)$ & 0.001 \\
\hline Pre-NLR, median (IQR) & $2.14(1.70-2.78)$ & $3.29(1.85-4.32)$ & 0.055 \\
\hline Pre-PLR, median (IQR) & $94.11(67.99-125.48)$ & $187.29(131.67-212.86)$ & $<0.001$ \\
\hline
\end{tabular}

Abbreviations: SD Standard deviation, IQR Interquartile range, CLI Critical limb ischemia, WBC White blood cell, MPV Mean platelet volume, pre-NLR Preoperative neutrophil-to-lymphocyte ratio, pre-PLR Preoperative platelet-to-lymphocyte ratio

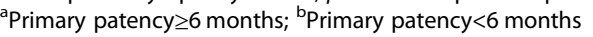

development, plaque rupture and thrombosis. Low lymphocyte count has been confirmed to be related to poor prognosis in patients with heart disease [23].In addition, lymphocytes play an important part in tissue healing, Iso et al. reported that lymphocyte count seems to be related to limb salvage rate of CLI patients [24].In the present study, lymphocytes in group B were lower than that of group A, which indicated that lymphocytes may be a protective factor in restenosis.

PLR represents two opposite associations which are superior to absolute platelet or lymphocyte counts. It is easy to perform in the blood test, and an increased PLR may yield further evidence on inflammatory response and the prothrombotic state [25]. It has been reported that the raised PLR was related to poor prognosis when patients suffered from coronary artery disease and aortic stenosis [12, 26-28]. In the present study, the pre-PLR was predictive of PP at 6 months, and the 6-month PP in the group of prePLR $<127.35$ was higher than that of pre-PLR $\geq$ 127.35 group, which should also be noticed during the postoperative treatment.
NLR was already tested as a marker of the response of the immune system and predicted the presence of atherosclerotic plaques in elderly patients [29]. Li et al. [30] concluded that higher pre-NLR and prePLR levels were independent risk factors for the development of in-stent restenosis in patients who underwent drug-eluting stent implantation for coronary chronic total occlusion lesions. However, in the study, pre-NLR was not an independent predictor of $\mathrm{PP}$ at 6 months, which is in accordance with our previous report [16]. Larger samples are still needed to confirm our conclusion in the future.

It is known that DCB with antiproliferative drugs has the effect of inhibiting intimal hyperplasia and reducing the occurrence of restenosis [31]. However, in complex FPD including severe calcium, long segment lesions, the applications of DCB angioplasty are often excluded for lesions with flow-limiting dissection or high residual narrowing after pretreatment with uncoated balloon, and bail-out stenting has to be used in some cases [32] In the present study, lesion length was divided into groups based on the median length, and lesion length > 
Table 2 Logistic regression analysis for predicting 6-month primary patency

\begin{tabular}{|c|c|c|c|c|c|c|}
\hline & \multicolumn{3}{|c|}{ Univariate analysis } & \multicolumn{3}{|c|}{ Multivariate analysis } \\
\hline & $\overline{\mathrm{OR}}$ & $\mathrm{Cl}$ & $p$ & $\overline{O R}$ & $\mathrm{Cl}$ & $P$ \\
\hline Man & 5.769 & $0.669,47.587$ & 0.104 & & & \\
\hline Age & 1.029 & $0.972,1.089$ & 0.321 & & & \\
\hline Hypertension & 1.378 & $0.387,4.903$ & 0.620 & & & \\
\hline Smoke & 0.476 & $0.144,1.578$ & 0.225 & & & \\
\hline Diabetes & 2.586 & $0.740,9.042$ & 0.137 & & & \\
\hline Hyperlipemia & 1.434 & $0.420,4.892$ & 0.565 & & & \\
\hline Cardiovascular disease & 2.619 & $0.829,8.276$ & 0.101 & & & \\
\hline CLI & 2.833 & $0.894,8.975$ & 0.077 & 1.992 & $0.446,8.286$ & 0.381 \\
\hline Severe calcium & 0.653 & $0.071,6.037$ & 0.708 & & & \\
\hline Total occlusion & 0.926 & $0.277,3.099$ & 0.901 & & & \\
\hline Outflow (1) & 3.500 & $0.95,12.898$ & 0.060 & 2.360 & $0.494,11.282$ & 0.282 \\
\hline Outflow (2) & 1.071 & $0.233,4.919$ & 0.929 & 0.631 & $0.096,4.159$ & 0.632 \\
\hline Lesion length $>10 \mathrm{~cm}$ & 5.100 & $1.448,17.965$ & 0.011 & 4.305 & $1.061,17.465$ & 0.041 \\
\hline Bailout-stent & 1.143 & $0.207,6.303$ & 0.878 & & & \\
\hline WBC & 1.042 & $0.831,1.307$ & 0.719 & & & \\
\hline Pre-NLR & 1.210 & $0.960,1.524$ & 0.106 & & & \\
\hline MPV & 0.545 & $0.283,1.050$ & 0.069 & 0.850 & $0.448,1.612$ & 0.618 \\
\hline Pre-PLR & 1.011 & $1.003,1.020$ & 0.008 & 1.008 & $1.001,1.016$ & 0.031 \\
\hline
\end{tabular}

Abbreviations: OR Odds ratio, CI Confidence interval, CLI Critical limb ischemia, WBC White blood cell, MPV Mean platelet volume, pre-NLR Preoperative neutrophilto-lymphocyte ratio, Pre-PLR Preoperative platelet-to-lymphocyte ratio

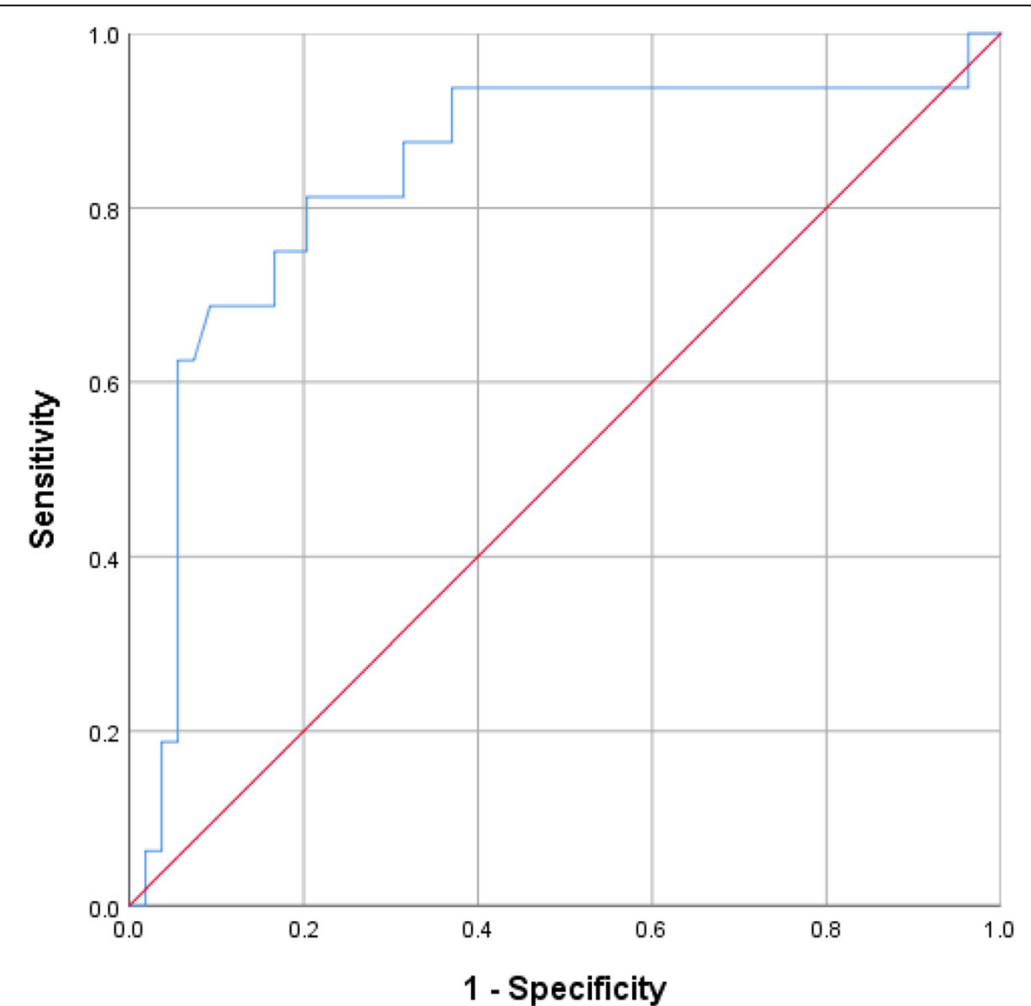

Fig. 1 Receiver operating characteristic (ROC) curve for 6-month primary patency according to preoperative platelet-to-lymphocyte ratio. The area under the ROC curve was 0.839 , and the sensitivity and specificity were 81.3 and $79.6 \%$, respectively 
$10 \mathrm{~cm}$ was a risk factor in 6-month $\mathrm{PP}$, while it seems that severe calcium has no influence in 6-month PP. It has been widely recognized that severe calcium can increase the technical difficulty and reduce the durability of endovascular therapy in the FPD [4, 15, 33], however there was not a standard classification of calcium degree till now. So, it is important to define an appropriate calcification grading system which can have a good relationship with the major procedure outcome.

Several limitations of this study deserve attention. First, this is a small size and single-center retrospective analysis which may lead to the selection bias and a type II error. Secondly, we did not dynamically monitor the changes in PLR after treatment. Finally, other inflammatory mediators in the blood sample were not involved in this study.

\section{Conclusion}

The present study showed that pre-PLR was an independent risk factor in predicting 6-month PP. Pre-PLR, a simple and easy-to-obtain blood cell parameter, tends to be higher in the restenosis group after FPD receiving DCB angioplasty. Preoperative elevated PLR maybe helpful to identify those at risk of early restenosis and lay the groundwork for novel approaches for preventing restenosis.

\section{Abbreviations}

pre-PLR: Preoperative platelet-to-lymphocyte ratio; PP: Primary patency; DCB: Drug-coated balloon; FPD: Femoropopliteal disease; PTA: Percutaneous transluminal angioplasty; pre-NLR: Preoperative neutrophil-lymphocyte ratio; WBC: White blood cell; MPV: Mean platelet volume; ASA: Acetylsalicylic acid; OR: Odds ratio; Cl: Confidence interval; ROC: Receiver operating characteristic; CLI: Critical limb ischemia

\section{Acknowledgements}

The authors would like to thank all the investigators and support staff involved in the completion of this study.

\section{Authors' contributions}

$Y Z$ and JZ conceived and designed the study. $Y Z$ and $Z C$ collected and analyzed the data. $Y Z$ and $Z C$ wrote the article. JZ and $Z L$ revised the article. These authors contributed equally to this manuscript. The manuscript was read and approved by all authors.

\section{Funding}

The author(s) received no financial support for the research, authorship, and/ or publication of this article.

\section{Availability of data and materials}

The raw data of this study will not be shared publically because they will be applied for further researches of this series but the datasets used and/or analyzed during the current study are available from the corresponding author on reasonable request.

\section{Ethics approval and consent to participate}

The Shengjing Hospital of China Medical University institutional review board approved this retrospective study with a waiver of informed consent.

\section{Consent for publication}

Not applicable.

\section{Competing interests}

The authors declare that they have no competing interests.

Received: 20 April 2019 Accepted: 19 December 2019

Published online: 09 January 2020

\section{References}

1. Joviliano EE, Piccinato CE, Dellalibera-Joviliano R, Moriya T, Evora PR. Inflammatory markers and restenosis in peripheral percutaneous angioplasty with intravascular stenting: current concepts. Ann Vasc Surg. 2011;25(6):846-55.

2. Signorelli SS, Fiore V, Malaponte G. Inflammation and peripheral arterial disease: the value of circulating biomarkers (review). Int J Mol Med. 2014; 33(4):777-83.

3. Stone PA, Yacoub M. Inflammatory biomarkers in peripheral arterial disease. Semin Vasc Surg. 2014;27(3-4):148-51.

4. Fanelli F, Cannavale A, Gazzetti M, Lucatelli P, Wlderk A, Cirelli C, d'Adamo A, Salvatori FM. Calcium burden assessment and impact on drug-eluting balloons in peripheral arterial disease. Cardiovasc Intervent Radiol. 2014; 37(4):898-907.

5. von Hundelshausen $P$, Weber C. Platelets as immune cells: bridging inflammation and cardiovascular disease. Circ Res. 2007:100(1):27-40.

6. May AE, Seizer P, Gawaz M. Platelets: inflammatory firebugs of vascular walls. Arterioscler Thromb Vasc Biol. 2008;28(3):s5-10.

7. Aukrust P, Halvorsen B, Ueland T, Michelsen AE, Skjelland M, Gullestad L, Yndestad A, Otterdal K. Activated platelets and atherosclerosis. Expert Rev Cardiovasc Ther. 2010;8(9):1297-307.

8. Major AS, Fazio S, Linton MF. B-lymphocyte deficiency increases atherosclerosis in LDL receptor-null mice. Arterioscler Thromb Vasc Biol. 2002:22(11):1892-8.

9. Liu WY, Lin SG, Wang LR, Fang CC, Lin YQ, Braddock M, Zhu GQ, Zhang Z, Zheng $\mathrm{MH}$, Shen FX. Platelet-to-lymphocyte ratio: a novel prognostic factor for prediction of 90-day outcomes in critically ill patients with diabetic ketoacidosis. Medicine (Baltimore). 2016;95(4):e2596.

10. Demirdal T, Sen P. The significance of neutrophil-lymphocyte ratio, plateletlymphocyte ratio and lymphocyte-monocyte ratio in predicting peripheral arterial disease, peripheral neuropathy, osteomyelitis and amputation in diabetic foot infection. Diabetes Res Clin Pract. 2018;144:118-25.

11. Uzun F, Erturk M, Cakmak HA, Kalkan AK, Akturk IF, Yalcin AA, Uygur B, Bulut $\mathrm{U}, \mathrm{Oz} \mathrm{K}$. Usefulness of the platelet-to-lymphocyte ratio in predicting longterm cardiovascular mortality in patients with peripheral arterial occlusive disease. Postep Kardiol Interwencyjnej. 2017;13(1):32-8.

12. Zhou D, Wang G, Fan Y, Wan Z, Liu X. Platelet to lymphocyte ratio is associated with the severity of coronary artery disease and clinical outcomes of percutaneous coronary intervention in the Chinese Han population. Exp Ther Med. 2017;13(2):731-8.

13. Osadnik T, Wasilewski J, Lekston A, Strzelczyk J, Kurek A, Gonera M, Gawlita M, Regula R, Bujak K, Szygula-Jurkiewicz B, et al. The platelet-to-lymphocyte ratio as a predictor of all-cause mortality in patients with coronary artery disease undergoing elective percutaneous coronary intervention and stent implantation. J Saudi Heart Assoc. 2015;27(3):144-51.

14. Idil Soylu A, Arikan Cortcu S, Uzunkaya F, Atalay YO, Bekci T, Gungor L, Belet $U$. The correlation of the platelet-to-lymphocyte ratio with the severity of stenosis and stroke in patients with carotid arterial disease. Vascular. 2017; 25(3):299-306.

15. Tepe G, Beschorner U, Ruether C, Fischer I, Pfaffinger P, Noory E, Zeller T. Drug-eluting balloon therapy for Femoropopliteal occlusive disease: predictors of outcome with a special emphasis on calcium. J Endovasc Ther 2015;22(5):727-33

16. Zhen Y, Chang Z, Liu Z, Zheng J. Relationship between postoperative neutrophil-lymphocyte ratio and 6-month primary patency of percutaneous Transluminal angioplasty in Femoropopliteal disease with drug-coated and uncoated balloons. Angiology. 2018;70(3):244.

17. Massberg S, Brand K, Grüner S, Page S, Müller E, Müller I, Bergmeier W, Richter T, Lorenz M, Konrad I, et al. A critical role of platelet adhesion in the initiation of atherosclerotic lesion formation. J Exp Med. 2002;196(7):887-96.

18. Lievens D, von Hundelshausen P. Platelets in atherosclerosis. Thromb Haemost. 2011:106(5):827-38.

19. Huo Y, Schober A, Forlow SB, Smith DF, Hyman MC, Jung S, Littman DR, Weber C, Ley K. Circulating activated platelets exacerbate atherosclerosis in mice deficient in apolipoprotein E. Nat Med. 2003;9(1):61-7. 
20. Suades R, Padro T, Vilahur G, Badimon L. Circulating and platelet-derived microparticles in human blood enhance thrombosis on atherosclerotic plaques. Thromb Haemost. 2012;108(6):1208-19.

21. Ulich TR, del Castillo J, Ni RX, Bikhazi N, Calvin L. Mechanisms of tumor necrosis factor alpha-induced Lymphopenia, neutropenia, and biphasic Neutrophilia: a study of lymphocyte recirculation and hematologic interactions of TNFa with endogenous mediators of leukocyte trafficking. J Leukoc Biol. 1989:45:155-67.

22. Ketelhuth DFJ, Hansson GK. Adaptive response of $T$ and $B$ cells in atherosclerosis. Circ Res. 2016;118(4):668-78.

23. Núñez J, Miñana G, Bodí V, Núñez E, Sanchis J, Husser O, Llàcer A. Low lymphocyte count and cardiovascular diseases. Curr Med Chem. 2011;18(21): 3226-33.

24. Iso Y, Soda T, Sato T, Sato R, Kusuyama T, Omori Y, Shoji M, Koba S, Katagiri T, Kobayashi Y, et al. Impact of implanted bone marrow progenitor cell composition on limb salvage after cell implantation in patients with critical limb ischemia. Atherosclerosis. 2010;209(1):167-72.

25. Lee YSG, Baradi A, Peverelle M, Sultani R, Adams H, Garlick J, Wilson AM. Usefulness of platelet-to-lymphocyte ratio to predict long-term all-cause mortality in patients at high risk of coronary artery disease who underwent coronary angiography. Am J Cardiol. 2018;121(9):1021-6.

26. Yayla Ç, Açikgöz SK, Yayla KG, Açikgöz E, Canpolat U, Kirbaş Ö, Öksüz F, Özcan F, Akboğa MK, Topaloğlu S, et al. The association between platelettolymphocyte ratio and inflammatory markers with the severity of aortic stenosis. Biomark Med. 2016;10(4):367.

27. Trakarnwijitr I, Li B, Adams H, Layland J, Garlick J, Wilson A. Age modulates the relationship between platelet-to-lymphocyte ratio and coronary artery disease. Int J Cardiol. 2017;248:349-54.

28. Sun XP, Li J, Zhu WW, Li DB, Chen H, Li HW, Chen WM, Hua Q. Impact of platelet-to-lymphocyte ratio on clinical outcomes in patients with STsegment elevation myocardial infarction. Angiology. 2017;68(4):346-53.

29. Corriere T, Di Marca S, Cataudella E, Pulvirenti A, Alaimo S, Stancanelli B, Malatino L. Neutrophil-to-lymphocyte ratio is a strong predictor of atherosclerotic carotid plaques in older adults. Nutr Metab Cardiovasc Dis. 2018;28(1):23-7.

30. Li C, Shen Y, Xu R, Dai Y, Chang S, Lu H, Dong Z, Deng J, Qian J, Ge J. Evaluation of Preprocedural laboratory parameters as predictors of drugeluting stent restenosis in coronary chronic Total occlusion lesions. Angiology. 2018;70(3):272.

31. Portugaller RH, Kalmar PI, Deutschmann $\mathrm{H}$. The eternal tale of dialysis access vessels and restenosis: are drug-eluting balloons the solution? J Vasc Access. 2014;15(6):439-47.

32. Shammas NW, Coiner D, Shammas G, Jerin M. Predictors of provisional stenting in patients undergoing lower extremity arterial interventions. Int Angiol. 2011;20(2):95-100.

33. Rocha-Singh KJ, Zeller T, Jaff MR. Peripheral arterial calcification: prevalence, mechanism, detection, and clinical implications. Catheter Cardiovasc Interv. 2014;83(6):E212-20.

\section{Publisher's Note}

Springer Nature remains neutral with regard to jurisdictional claims in published maps and institutional affiliations.

Ready to submit your research? Choose BMC and benefit from:

- fast, convenient online submission

- thorough peer review by experienced researchers in your field

- rapid publication on acceptance

- support for research data, including large and complex data types

- gold Open Access which fosters wider collaboration and increased citations

- maximum visibility for your research: over $100 \mathrm{M}$ website views per year

At $\mathrm{BMC}$, research is always in progress.

Learn more biomedcentral.com/submissions 